kenntnisse zur Gemeinsamkeit dominieren ungebrochen nationale Interessen und Rationalitäten. Ihre „praxisnahe“ Analyse deckt sich mit Marcel Kotthoffs Schlussthese, dass beide Länder „von ihrem angestrebten Ziel, bei zwischenstaatlichen Krisen und innerstaatlichen Konflikten wirkungsvoll und militärisch sowie zivil effizient agieren zu können, noch weit entfernt" sind.

Ursula Mathis-Mosers Exposé über das „französische Chanson, nationales Aushängeschild auf Europakurs?" rundet den gelungenen Sammelband ab.

Udo Kempf

2 Ebenda, S. 251.

\title{
Die Sozialistische Partei und die französische Verfassungsreform: weder überraschend noch originell
}

Buscke, Isabelle: Die französische Verfassungsreform. Eine verhandlungstheoretische Analyse, VDM Verlag Dr. Müller, Saarbrücken 2010, 104 Seiten, € 49,-.

Am 21. Juli 2008 hat der französische Kongress (gemeinsame Sitzung von Nationalversammlung und Senat) mit äußerst knapper Mehrheit (539 Stimmen; nötig waren 538) die bislang umfangreichste Änderung der Verfassung der V. Republik beschlossen. Ihr zentraler Bestandteil ist eine Stärkung des Parlaments, ohne dass dadurch die Gesamtstruktur der präsidentialistisch akzentuierten Verfassungsordnung grundlegend verändert würde.

Isabelle Buscke untersucht in ihrer Arbeit (vermutlich eine studentische Abschlussarbeit) nicht den Inhalt dieser Verfassungsreform, sondern ihr Zustandekommen. Sie will herausfinden, „warum die Sozialistische Partei trotz des breiten Konsenses in der Sache" und obwohl die Vorlage "Jahrzehnte alte Kernforderungen der PS beinhaltete" (S. 6), ihr nicht zugestimmt hat. Dabei legt sie das von Robert Putnam für die Analyse von Verhandlungen in den internationalen Beziehungen entwickelte Konzept zugrunde und überträgt es auf die innerstaatliche Ebene. Den zwischenstaatlichen Verhandlungen entsprechen jene zwischen der parlamentarischen Mehrheit und der Opposition, also im Wesentlichen zwischen der Union pour un Mouvement Populaire (UMP) und der PS; denen der innerstaatlichen Ebene, auf der das Ergebnis akzeptiert und ratifiziert werden muss, entsprechen die Verhandlungen zwischen den PS-Parlamentariern und der Sozialistischen Partei. Die Verfasserin berücksichtigt dagegen bewusst nicht, „warum die UMP (...) den Sozialisten nicht mehr Zugeständnisse machen konnte" (S. 9). Man muss wohl präzisieren, dass ein weiteres Entgegenkommen etwa hinsichtlich des Wahlmodus der Senatoren in der UMP, vor allem bei ihren Senatoren, nicht durchsetzbar war, selbst wenn Präsident Nicolas Sarkozy es gewollt hätte. Die Beschränkung auf die PS ist zwar vertretbar, doch kann ihre Ablehnung der Verfassungsänderung kaum zutreffend beurteilt werden, wenn man die andere Seite, eben die UMP, ganz außer Acht lässt.

Die Verfasserin geht von der zutreffenden Feststellung aus, dass die PS-Fraktionen in Nationalversammlung und Senat in der Frage Zustimmung oder Ablehnung gespalten waren. Es trifft auch zu, dass bei einem derart wichtigen Gegenstand eine Einigung höchst 
wünschenswert erschien, die Parlamentarier sich also letztlich der Fraktionsdisziplin beugen mussten. Wäre die Abstimmung freigegeben worden und hätten die PS-Parlamentarier auf ihr in der Verfassung verbrieftes freies Mandat (Art. 27) gepocht, so hätte es nicht die Zitterpartie und den bis zuletzt ungewissen Ausgang gegeben, denn eine Reihe von ihnen hätte zugestimmt. Schließlich musste das Votum der Parlamentarier von der Partei akzeptiert werden.

Aber was heißt Partei? Die PS ist ein kompliziertes Gebilde. Sie besteht aus den verschiedenen Führungsgremien, den Funktionären, den aktiven Parteimitgliedern („militants“) und den Sympathisanten, die in der Regel zumindest potentielle Wähler sind. Zu berücksichtigen sind auch die besonders ausgeprägten innerparteilichen Strömungen („,courants“) mit ihrer unterschiedlichen Stärke. Die PS-Anhänger, also Sympathisanten beziehungsweise Wähler, sprachen sich in einer Umfrage bis auf eine Ausnahme (Rederecht des Staatspräsidenten im Parlament) mit sehr klaren Mehrheiten für die abgefragten Inhalte der Reform aus. Da es keine Mitgliederbefragung gab, ist die Einstellung der Parteibasis nicht zuverlässig zu ermitteln. Gestützt auf Internet-Blogs, über deren mangelnde Repräsentativität sich die Verfasserin im Klaren ist, hat sie erwartungsgemäß die Reform ablehnende wie befürwortende Antworten gefunden. Folglich war die Position der Parteiführung, an die sich die Parlamentarier traditionell zu halten hatten, ausschlaggebend. Ob es eine formelle Abstimmung etwa im Secrétariat national gegeben hat, wird nicht mitgeteilt. Es heißt nur allgemein, gestützt auf einen Le Monde-Artikel, „dass die Bemühungen einiger PS-Abgeordneter, mit der Regierungspartei UMP zu einem Kompromiss zu gelangen, von der Parteiführung - insbesondere vom Parteivorsitzenden François Hollande - nicht unterstützt wurden“ (S. 73). Die Rolle des Parteivorsitzenden schätzt die Verfasserin als sehr wichtig, wohl als entscheidend ein. François Hollande legte schon früh fünf Maximalforderungen vor (S. 71 f.), von deren Annahme er die Zustimmung abhängig machte. Es dürfte ihm klar gewesen sein, dass sie von der UMP nicht gänzlich akzeptiert werden würden. Es mag durchaus sein, dass er sich von einer ablehnenden Haltung eine Verbesserung seiner Chancen für eine Kandidatur für die Präsidentenwahl 2012 erhofft hat.

Warum stimmte also die PS nicht zu? Die Antwort, die die Verfasserin aufgrund ihrer verhandlungstheoretischen Analyse gibt, ist weder überraschend noch originell. Neben inhaltlichen Bedenken (besonders hinsichtlich des Wahlmodus der Senatoren) habe es auch „parteiinterne Gründe“ (S. 83) gegeben: Die PS wollte ihrem Erzfeind Nicolas Sarkozy keinen derartigen Erfolg gönnen. Was nahezu alle Beobachter schon so sahen, wird nun, unter Berücksichtigung des „win-set“ und des „acceptability-set“ der PS im „Two-Level-Game“, methodisch ordentlich abgesichert untermauert. 